\title{
Interstitial Lung Diseases: Introduction
}

Interstitial lung diseases (ILD) represent a large and heterogeneous group of lower respiratory tract disorders. They frequently share several clinical, radiographic and physiologic features. Moreover, inflammation, tissue injury and fibrosis often develop in the same patient, even if to a different extent and with a varying outcome.

Immunological data have allowed clinicians to better understand the pathogenesis of most ILD and to carefully design clinical studies to improve treatment. However, rare ILD and new insights in idiopathic interstitial pneumonias (IIPs) still challenge the clinician with regard to the correct diagnosis and the appropriate treatment.

The role of the clinician has recently been reconsidered. It has been emphasized that the diagnosis of most ILDs - and in particular of idiopathic pulmonary fibrosis (IPF) - cannot be left to radiologists and/or pathologists alone. The diagnosis should result from the cooperation between the clinician and both the radiologist and the pathologist.

The aim of this series in Respiration is twofold:

(1) To give clinicians an update on the major tools available to them to distinguish among dozens of different forms of ILD. The first of three articles, in particular, will review the possibilities high resolution computed tomography (HRCT) can offer for the differential diagnosis and follow-up of most ILDs. The second article will discuss when bronchoscopy, bronchoalveolar lavage (BAL), open lung biopsy and other invasive techniques should be performed. Finally, the third article will help elucidate the physiopathological abnormalities observed in different forms of ILD and clarify the use of some respiratory parameters to predict the outcome of surgical interventions.

(2) To allow the clinician to differentiate between wellknown ILDs such as sarcoidosis and hypersensitivity pneumonitis and the so-called 'rare' or 'orphan' diseases. A special topic will focus on the bronchiolar involvement in ILD. Furthermore, the clinician will be given the opportunity to identify the different forms of IPF and to review the therapeutic strategies that may be applied to prolong patients' survival and quality of life.

The authors of these articles are highly qualified and their expertise in the field of ILD is well known. However, due to the limited space allowed for each chapter, a lot of information will be omitted. For this reason, the authors have been asked to write an essential and updated bibliography. It will be the best 'algorithm' to develop further aspects of this very difficult field in Respiratory Medicine.

\author{
Guest Editors \\ Dario Olivieri, Parma \\ Venerino Poletti, Forlì \\ Maurizio Zompatori, Parma
}

\begin{tabular}{ll}
\hline KARGER & (c) 2004 S. Karger AG, Basel \\
0025-7931/04/0711-0003\$21.00/0 \\
$\begin{array}{l}\text { Fax +4161306 1234 } \\
\begin{array}{l}\text { E-Mail karger@karger.ch } \\
\text { www.karger.com }\end{array}\end{array}$ & $\begin{array}{l}\text { Accessible online at: } \\
\text { www.karger.com/res }\end{array}$
\end{tabular}

